\title{
Attitudes towards vasectomy and its acceptance as a method of contraception among clinical-year medical students in a Malaysian private medical college
}

\author{
Saw $\underline{\text { Ohn Mar }}{ }^{1}$, MMedSc, FRCog, Osman $\underline{A l i}^{1}$, MPH, PhD, Sugathan Sandheep ${ }^{1}$, MD, DPH, Zul $\underline{\text { Husayni }}^{1}$, MBBS,
} Muhammad Zuhri ${ }^{1}$, MBBS

\begin{abstract}
INTRODUCTION This study explored attitudes towards vasectomy and its acceptance as a method of contraception among clinical-year medical students, and determined the association between their demographic characteristics, and attitudes and acceptance.

METHODS A cross-sectional survey was conducted among clinical-year medical students from a Malaysian private medical college using a self-administered questionnaire.

RESULTS There were 330 participants with a female preponderance and a mean age of $22.0 \pm 1.1$ years. The largest proportion of respondents were from Year 3. The vast majority were ethnically Malay (91.8\%) and followed Islam (92.4\%). Overall, $60.9 \%$ of participants had a positive attitude towards vasectomy and $76.0 \%$ showed good acceptance. Gender, academic year, ethnicity and religion variables were not associated with attitudes and acceptance $(p>0.05)$. A significantly higher proportion of male respondents thought that vasectomy was religiously forbidden and would give a bad impression. A significantly higher proportion of Year 5 students agreed to the statement 'I would recommend vasectomy to relatives, friends and people close to me' compared to Year 3 and 4 students.

CONCLUSION Students' perception of vasectomy as a contraceptive method was encouraging. Our results suggest that their knowledge improved as medical training progressed, and attitudes evolved for the better irrespective of their traditional, cultural and religious beliefs - highlighting the importance of providing students with evidence-based learning about male sterilisation, which is more cost-effective and is associated with lower morbidity than female sterilisation. A qualitative study involving students from different ethnicities and religions would provide a better understanding of this subject.
\end{abstract}

Keywords: acceptance, attitude, Malaysia, medical students, vasectomy

\section{INTRODUCTION}

The population of Malaysia was estimated to be 31 million as of January 2016.(1) In 2014, the country's fertility rate was two per woman aged 15-49 years. ${ }^{(2)}$ The contraceptive prevalence rate in Malaysia for all methods was $55.0 \%$, while the rate of vasectomy, a method of permanent sterilisation for men, was very low $(0.1 \%)$ compared to female sterilisation $(6.6 \%))^{(3)}$

The major ethnic groups in multiracial Malaysia are the Malays or Bumiputera (67.4\%), Chinese $\left(24.6 \%\right.$ ) and Indians $(7.3 \%) .{ }^{(4)}$ Islam is most widely followed, by $61.3 \%$ of citizens, followed by Buddhism (19.8\%), Christianity (9.2\%), Hinduism (6.3\%) and others. ${ }^{(5)}$ Therefore, healthcare providers need to be aware of and recognise the potential influence of divergent religious and cultural factors on the acceptance and practices of different contraceptive methods among the varied population. Even within a religion, teachings on this subject may be interpreted in variable ways. Equally important is the role of cultural factors in couples' decisions about family size and contraception. ${ }^{(6)}$

Studies on the acceptance and practices of contraception among various populations have drawn interesting conclusions. For instance, certain misconceptions have been reported among Indian medical students about modern contraceptive methods and the impact of sex education. ${ }^{(7)}$ Although the students demonstrated positive attitudes towards contraception and premarital counselling, the influence of traditional values and negative provider attitudes was also recognised. ${ }^{(7)}$ More than $80 \%$ of Nigerian resident doctors were convinced that the average male Nigerian would not accept vasectomy, while over $60 \%$ considered female sterilisation to be a more appropriate permanent contraceptive method. ${ }^{(8)}$ An Iranian study, on the other hand, reported an increasing trend in vasectomy rates from 2005 to 2007 and significant positive associations between male and female educational levels and opting for vasectomy. ${ }^{(9)}$ Even so, another Indian study reported that literacy was not a prerequisite for choosing vasectomy. ${ }^{(10)}$ Current information on medical students' views of vasectomy, a procedure that is widely considered to be superior to female sterilisation in terms of morbidity and cost-effectiveness, ${ }^{(11)}$ would help educationists to understand prevailing perceptions.

In the Bachelor of Medicine, Bachelor of Surgery programme at Universiti Kuala Lumpur Royal College of Medicine Perak (UniKL RCMP), Perak, Malaysia, more than $90 \%$ of the students are Malay and Muslim, with a minority who are Indian, Chinese and or of other ethnicities. The female-to-male ratio among medical

${ }^{1}$ Faculty of Medicine, Universiti Kuala Lumpur Royal College of Medicine Perak, Ipoh, Malaysia

Correspondence: Dr Saw Ohn Mar, Associate Professor, Obstetrics and Gynaecology, Faculty of Medicine, Universiti Kuala Lumpur, Royal College of Medicine Perak, No 3 , Jalan Greentown, 30450 Ipoh, Perak, Malaysia.sawohnmar@unikl.edu.my 
students is 2:1. Students receive some contraception-related instruction and undergo related learning activities during the preclinical and clinical years.

This study aimed to gain insight into medical students' views of male sterilisation as a contraceptive method, which remains an unpopular choice among Malaysian couples. This would facilitate evidence-based learning about male sterilisation during their training on methods of family planning. We also aimed to determine students' attitudes towards and acceptance of vasectomy, and the association of their attitudes and acceptance with demographic variables such as gender, academic year of study, ethnicity and religion. The correlation between students attitudes and their acceptance of vasectomy was also analysed.

\section{METHODS}

This was a cross-sectional survey of medical students using a self-administered questionnaire. The study was approved by the medical research ethics committee at the Faculty of Medicine, UniKL RCMP, Perak, Malaysia, and was conducted during the period between May 2015 and June 2015 at the institution.

The questionnaire included a few questions on the demographic background of the participants, seven questions for assessing their attitudes towards vasectomy as a contraceptive method and two strong statement questions to evaluate their acceptance of vasectomy. The questionnaire was developed by the study authors and validated by two experts from different specialties. A pilot study was conducted before the actual survey.

The required sample size was determined as 207 using Cochran's formula adjusted for small populations, based on the fact that acceptance of vasectomy was around $40 \%$ among Muslim-majority resident gynaecologists. ${ }^{(8)}$ All clinical-year students were approached for participation, and the nature and purpose of the study was explained in detail. Written consent was obtained from those willing to participate. Out of a total of 472 students, 330 students participated in the survey, a response rate of $69.9 \%$.

Scores were assigned according to responses to the statements. For each question, a response that reflected a positive attitude towards or good acceptance of vasectomy as a contraceptive method was scored as 2, a 'not sure' response was scored as 1 and a response that implied a negative attitude or poor acceptance was scored as 0 . For the attitude questions, the median score was 9 , and hence $\geq 9$ was rated as positive and $<9$ was considered negative. For acceptance of vasectomy, the median score was 2 , so that $\geq 2$ was taken as good acceptance, while scores of 1 and 0 were considered to be poor acceptance.

Analyses were performed to determine any relationship between the respondents' demographic variables, and their attitudes towards and acceptance of vasectomy, as well as to ascertain the association between these variables and responses to individual questions. Data was analysed to determine the association between attitudes and acceptance towards vasectomy among the study population. SPSS Statistics version 17 (SPSS Inc, Chicago, IL, USA) was used for the statistical analysis.
Table I. Demographic characteristics of the study population (n= 330).

\begin{tabular}{|ll|}
\hline Variable & No. (\%) \\
\hline Gender & \\
\hline Male & $108(32.7)$ \\
\hline Female & $222(67.3)$ \\
\hline Academic year & $140(42.4)$ \\
\hline Yr 3 & $114(34.5)$ \\
\hline Yr 4 & $76(23.0)$ \\
\hline Yr 5 & \\
\hline Ethnicity & $303(91.8)$ \\
\hline Malay & $10(3.0)$ \\
\hline Indian & $9(2.7)$ \\
\hline Chinese & $8(2.4)$ \\
\hline Other & \\
\hline Religion & $305(92.4)$ \\
\hline Islam & $9(2.7)$ \\
\hline Hinduism & $8(2.4)$ \\
\hline Christianity & $6(1.8)$ \\
\hline Buddhism & $2(0.6)$ \\
\hline Other & \\
\hline
\end{tabular}

\section{RESULTS}

The mean age of the respondents was $22.0 \pm 1.1$ years and the majority were female $(67.3 \%)$. The largest proportion of respondents were from Year $3(42.4 \%)$. A vast majority were ethnically Malay (91.8\%) and followed Islam (92.4\%) (Table I).

Most respondents agreed that vasectomy was one of the best contraceptive methods (75.8\%) and supported the statement 'Vasectomy is a good choice for couples who have completed their family' (69.1\%). Only $17.0 \%$ of the respondents believed that vasectomy was forbidden according to their religion and nearly $44.2 \%$ were unsure about this. Nearly half of the respondents agreed that vasectomy could be done under certain conditions even if it was forbidden in their religion (49.4\%). Only $14.8 \%$ of the students supported the statement that vasectomy carried a bad impression for the person opting for it, and $21.2 \%$ assumed that a man who had vasectomy would be prone to be promiscuous. Nearly $42.7 \%$ of the respondents believed that vasectomy was an unusual contraceptive practice in Malaysia. Although 38.8\% of the students favoured vasectomy over female sterilisation, only $23.3 \%$ indicated that they would recommend the method to people they were close to. Nearly half of all the students were unsure about both questions related to the acceptance of vasectomy, even though they had received training on it as part of their medical education (Table II).

Overall, $60.9 \%$ of the respondents demonstrated a positive attitude towards vasectomy as a contraceptive method and $76.0 \%$ had good acceptance of vasectomy. There was no statistically significant association between attitudes or acceptance towards vasectomy and various demographic variables $(p>0.05$; Table III). However, there was a significant correlation between students' attitudes and their acceptance of vasectomy $(p<0.05$; Table IV). 
Table II. Survey findings on attitudes towards vasectomy and acceptance among medical students $(\mathbf{n}=\mathbf{3 3 0})$.

\begin{tabular}{|c|c|c|c|}
\hline \multirow[t]{2}{*}{ Statement } & \multicolumn{3}{|c|}{ No. (\%) } \\
\hline & Agree & Disagree & Not sure \\
\hline \multicolumn{4}{|l|}{ Attitude } \\
\hline Vasectomy is one of the best methods of contraception. & $250(75.8)$ & $20(6.1)$ & $60(18.2)$ \\
\hline Vasectomy is a good choice for couples who have completed their family. & $228(69.1)$ & $33(10.0)$ & $69(20.9)$ \\
\hline Vasectomy is forbidden according to your religion. & $56(17.0)$ & $128(38.8)$ & $146(44.2)$ \\
\hline Vasectomy can be done under certain conditions even if it is forbidden according to your religion. & $163(49.4)$ & $36(10.9)$ & $131(39.7)$ \\
\hline Vasectomy carries a bad impression for the person. & $49(14.8)$ & $187(56.7)$ & $94(28.5)$ \\
\hline Vasectomy is an unusual contraceptive practice in Malaysia. & $141(42.7)$ & $70(21.2)$ & $119(36.1)$ \\
\hline A man who has vasectomy would be prone to be promiscuous. & $70(21.2)$ & $78(23.6)$ & $182(55.2)$ \\
\hline \multicolumn{4}{|l|}{ Acceptance } \\
\hline $\begin{array}{l}\text { I would favour vasectomy over female sterilisation if the couple seek a permanent } \\
\text { method of contraception. }\end{array}$ & $128(38.8)$ & $51(15.5)$ & $151(45.8)$ \\
\hline I would recommend vasectomy to relatives, friends or people close to me. & $77(23.3)$ & $84(25.5)$ & $169(51.2)$ \\
\hline
\end{tabular}

Table III. Association between demographic variables and medical students' attitudes towards and acceptance of vasectomy ( $\mathrm{n}=330$ ).

\begin{tabular}{|c|c|c|c|c|c|c|}
\hline \multirow[t]{3}{*}{ Variable } & \multicolumn{3}{|c|}{ Attitude } & \multicolumn{3}{|c|}{ Acceptance } \\
\hline & \multicolumn{2}{|c|}{ No. (\%) } & \multirow[t]{2}{*}{ p-value } & \multicolumn{2}{|c|}{ No. (\%) } & \multirow[t]{2}{*}{ p-value } \\
\hline & Positive & Negative & & Good & Poor & \\
\hline Gender & & & 0.103 & & & 0.555 \\
\hline Female $(n=222)$ & $142(64.0)$ & $80(36.0)$ & & $171(77.0)$ & $51(23.0)$ & \\
\hline Male $(n=108)$ & $59(54.6)$ & $49(45.4)$ & & $80(74.1)$ & $28(25.9)$ & \\
\hline Academic year & & & 0.051 & & & 0.083 \\
\hline $\operatorname{Yr} 3(n=140)$ & $76(54.3)$ & $64(45.7)$ & & $98(70.0)$ & $42(30.0)$ & \\
\hline $\operatorname{Yr} 4(\mathrm{n}=114)$ & $79(69.3)$ & $35(30.7)$ & & 91 (79.8) & $23(20.2)$ & \\
\hline $\operatorname{Yr} 5(n=76)$ & $46(60.5)$ & $30(39.5)$ & & 62 (81.6) & $14(18.4)$ & \\
\hline Ethnicity & & & $0.316^{*}$ & & & $0.751^{*}$ \\
\hline Malay $(\mathrm{n}=303)$ & $186(61.4)$ & $117(38.6)$ & & $231(76.2)$ & $72(23.8)$ & \\
\hline Indian $(n=10)$ & $6(60.0)$ & $4(40.0)$ & & $7(70.0)$ & $3(30.0)$ & \\
\hline Chinese $(n=9)$ & $3(33.3)$ & $6(66.7)$ & & $6(66.7)$ & $3(33.3)$ & \\
\hline Other $(n=8)$ & $6(75.0)$ & $2(25.0)$ & & $7(87.5)$ & $1(12.5)$ & \\
\hline Religion & & & $0.267^{*}$ & & & $0.203^{*}$ \\
\hline Islam $(n=305)$ & $188(61.6)$ & $117(38.4)$ & & $232(76.1)$ & $73(23.9)$ & \\
\hline Hinduism $(n=9)$ & $6(66.7)$ & $3(33.3)$ & & $6(66.7)$ & $3(33.3)$ & \\
\hline Christianity $(n=8)$ & $5(62.5)$ & $3(37.5)$ & & $8(100.0)$ & $0(0)$ & \\
\hline Buddhism $(n=6)$ & $1(16.7)$ & $5(83.3)$ & & $3(50.0)$ & $3(50.0)$ & \\
\hline Other $(n=2)$ & $1(50.0)$ & $1(50.0)$ & & $2(100.0)$ & $0(0)$ & \\
\hline
\end{tabular}

*Fisher's exact test

Analysis results of the association between students' responses to the individual attitude questions and their demographic variables are shown in Table $\mathrm{V}$. There was no significant association between demographic variables and Questions 1, 2 or 6 in the attitude section. Students responded differently to attitude Question 3 ('Vasectomy is forbidden according to your religion') depending on their gender, academic year and religion, and these differences were statistically significant $(p<0.05)$. A higher percentage of male students supported this statement than female students. Similarly, a larger proportion of Year 3 students agreed to the statement when compared to Year 4 and Year 5 students. Students following Hinduism were more likely to give a negative ('disagree') response to the statement than students following other religions.
The students' response to attitude Question 4 ('Vasectomy can be done under certain conditions even if it is forbidden according to your religion') was significantly different according to gender, academic year, ethnicity and religion $(p<0.05)$. Students who were male, Year 3, ethnically Malay and following Islam were more likely to support this statement. For attitude Question 5 ('Vasectomy carries a bad impression for the person'), only gender was significantly associated with a positive response, with a much higher proportion of male students agreeing with it $(p<0.05)$. Being in Year 5, of Chinese ethnicity and following the Christian religion were significantly associated with a negative response to attitude Question 7 ('A man who has vasectomy would be prone to be promiscuous') $(p<0.05)$. 
Table IV. Association between attitudes towards vasectomy and its acceptance among medical students $(n=330)$.

\begin{tabular}{|clll|}
\hline Variable & \multicolumn{2}{c}{ No. (\%) } & p-value \\
\cline { 2 - 3 } & Good acceptance & Poor acceptance & \\
\hline Attitude & & 0.007 \\
\hline Good $(n=201)$ & $163(81.1)$ & $38(18.9)$ & \\
\hline Poor $(n=129)$ & $88(68.2)$ & $41(31.8)$ & \\
\hline
\end{tabular}

The only association found between responses to acceptance questions was for academic year, where being in Year 5 was associated with a positive response to the statement 'I would recommend vasectomy to relatives, friends or people close to $\mathrm{me}^{\prime}(\mathrm{p}<0.05 ;$ Table VI).

\section{DISCUSSION}

Globally, the use of modern contraceptive methods has increased slightly, from $54 \%$ in 1990 to $57.4 \%$ in 2015 . However, the rate of contraception usage by men was still a small proportion of the overall prevalence, and its usage was limited to condoms and vasectomy. ${ }^{(12)}$ The prevalence of vasectomy also varies widely around the world. For instance, the age-adjusted prevalence of vasectomy was high in New Zealand (44\%). ${ }^{(13)}$ According to the 2002 United States (USA) National Survey of Family Growth, the prevalence of vasectomy was $6 \%$ and the tubal ligation rate was $16 \%$; vasectomy was the fourth most commonly used contraceptive method. ${ }^{(14)}$ Conversely, the gap between male and female sterilisation rates was very large in India (1\% vs. $37.3 \%$ ) and China (4.5\% vs. $28.7 \%)$, and less so in the USA $(12.7 \%$ vs. $23.6 \%$ ) and Australia (13.7\% vs. $15.9 \%$ ), but a reverse trend was observed in the United Kingdom (21\% vs. 8\%). ${ }^{(15)}$ These figures show that cultural, traditional and religious factors influence the acceptance of vasectomy as a contraceptive method.

In our survey, medical students demonstrated an optimistic view of vasectomy as a method of contraception, with $60.9 \%$ of participants having a positive attitude and $76.0 \%$ showing good acceptance of vasectomy. Although a comparison with existing literature was not possible due to a lack of previous research data on medical students, the perception of vasectomy among our clinical-year medical students was quite encouraging, as over half of our participants demonstrated a positive attitude and acceptance of male sterilisation. At the same time, gender, academic year, ethnicity and religion as demographic variables did not influence their attitudes towards vasectomy, provided that they had enough knowledge on the subject. This result was in line with the findings of an Indian study that gender, area of upbringing and type of medical college did not change attitudes towards contraception. ${ }^{(7)}$

Vasectomy is briefly discussed in our medical curriculum as part of a contraception tutorial, during students' obstetrics and gynaecology postings in Year 3. In Year 4, students are clinically exposed to contraception in the field. In their final years or Year 5 , a role-play session is held so that students can learn how to apply their basic science knowledge, clinical knowledge and communication skills to help clients seeking advice on family planning. During this session, students get a chance to critically discuss each method of contraception, including vasectomy. It can thus be expected that medical students gain knowledge of the topic each year, and that their attitudes also change synchronously during the learning process. This was reflected in the significantly higher proportion of Year 5 students who responded positively to the statement 'I would recommend vasectomy to relatives, friends or people close to me' when compared to their juniors $(p=0.012)$ in our survey.

In the general population, the prevalence of vasectomy tends to be higher among men with higher education and income, while women with lower education and income have a higher prevalence of tubal sterilisation. ${ }^{(16)}$ In an Iranian population, a positive significant association was found between education levels among men and women and choosing to have a vasectomy. ${ }^{(9)}$ An Indian study also reported that acceptance of non-scalpel vasectomy increased with age, literacy, duration of marriage and number of children. ${ }^{(17)}$ Similarly, a Nigerian study reported that knowledge about vasectomy was the strongest single factor influencing the acceptance of vasectomy $(p=0.013) .^{(18)}$

A previous study found that only $5.8 \%$ of resident gynaecologists counselled for vasectomy, while nearly $90 \%$ of them often counselled for bilateral tubal ligation. ${ }^{(8)}$ In our survey, $38.8 \%$ of respondents agreed that vasectomy was a more favourable permanent contraception option than female sterilisation and $23.3 \%$ of respondents said that they would recommend it to people close to them. Based on our results, a comparatively higher proportion of these graduates were likely to include vasectomy as an option during family planning counselling in their medical practice. It should, however, be noted that our findings represent the opinions of a young, mostly unmarried and medically educated group that lacked real-life exposure. In an earlier study conducted among married male health workers at a university hospital in Nigeria, $60.4 \%$ of whom were medical doctors, $58.0 \%$ of respondents were unwilling to accept vasectomy as a contraceptive procedure. ${ }^{(19)}$ They found that the cadre of medical profession and awareness of vasectomy were significantly correlated with the willingness to accept vasectomy. ${ }^{(19)}$

Our finding that there was no significant correlation between the ethnicity of the respondents and their perceptions of vasectomy were not supported by findings from previous research. A study conducted among doctors revealed that the reasons for opposition to vasectomy included sociocultural, religious and psychological factors. ${ }^{(8)}$ Another study carried out among married men in the USA found that $13.3 \%$ of married men had vasectomy and it was associated with older age, greater number of biological children, non-Hispanic white ethnicity and having gone to a family planning clinic, while tubal sterilisation was more likely among men who had not attended college, those of older age and those with live births. ${ }^{(20)}$ In a report from a military database in the USA, white men had a higher rate of vasectomy than black men. ${ }^{(21)}$

Similarly, in our study, the religious beliefs of participants were not associated with attitudes towards vasectomy or its acceptance. However, students who were male, in Year 3 and following Islam were significantly likely to agree that vasectomy 
was forbidden according to their religion. Some studies have highlighted the importance of religious belief in the context of male sterilisation. For instance, Protestants had the highest rate of male sterilisation at 8.44 per 1,000 men, while Jewish people had the lowest, at 1.86 per 1,000 men.(21) According to a study carried out in a Sudanese population, men were more likely to make the decision against family planning, had widespread misconceptions about vasectomy and had very low acceptance towards vasectomy, although husbands were responsible for providing contraceptives when family planning was practised. (22) In a suburban Nigerian population, apart from a fear of side effects $(70.4 \%)$, the other major reason for nonapproval of family planning by men was their perception that family planning was against religion $(52.1 \%) .{ }^{(23)}$ In that study, the predictors of poor attitude towards family planning were not having formal education, the practice of polygamy and, to a lesser extent, being Muslim. In contrast, another study from Nigeria, in which $97.3 \%$ of participants were Christian married men working in a university environment, found that $62.7 \%$ had a positive attitude towards vasectomy, and there was a significant association between participants' level of knowledge and their attitude towards vasectomy. ${ }^{(24)}$ To the best of our knowledge, there is no research data from earlier studies on medical students with which to compare our results.

As mentioned in the literature relating to contraception and Islamic belief, vasectomy or tubectomy (i.e. tubal ligation) is permissible to prevent pregnancy as long as the procedure is temporary (i.e. reversible). ${ }^{(25)}$ The Buddhist approach towards contraception is based on the belief that it is wrong to kill for any reason, and therefore contraception is acceptable provided that it is to prevent conception and is not causing the death of the fertilised egg. ${ }^{(26)}$ Thus, vasectomy is a well-accepted method among Buddhists. There is no direct and easy answer to the question of whether vasectomy or tubal sterilisation is permissible for Christians, because the Bible does not directly address all of the moral and spiritual implications of many modern medical procedures such as vasectomy and tubal ligation. While some denominations (e.g. the Roman Catholic Church) and certain movements within the Christian community (e.g. Natural Family Planning) are firmly opposed to any type of contraception, many Christians of good faith and conscience view vasectomy and tubal ligation as acceptable methods of birth control.(27) Our research findings suggest that a majority of our students demonstrated the correct understanding and interpretation of their religious teachings and, at the same time, were able to apply their evidencebased knowledge to develop a correct outlook regardless of prior religious teachings.

We analysed the responses to the two attitude questions that related to negative perceptions of vasectomised men, Question 5 ('Vasectomy carries a bad impression for the person') and Question 7 ('A man who has vasectomy would be prone to be promiscuous'). Interestingly, a significantly higher proportion of male students agreed with Question 5 ( $p<0.05)$. In general, vasectomy was seen as one of the least favoured methods of family planning, and was associated with fear and weakness. Besides this, a previous study found that there was a tendency to describe sterilised men with negative, often derogatory terms, and that even men who had a positive experience with the procedure might choose not to reveal it to others in the community. ${ }^{(28)} \mathrm{A}$ recent study reported a list of factors contributing to negative attitudes towards vasectomy, including a perceived negative impact on physical strength, ability to work and sexual performance, together with perceived loss of masculinity, pride or social status. ${ }^{(29)}$ Although only $23.6 \%$ of our respondents disagreed in response to Question 7, this was strongly associated with students who were in Year 5, Chinese and following Christianity. Another study found that 'disinhibition towards male promiscuity' was another factor thought to contribute to negative attitudes towards vasectomy. ${ }^{(29)}$ A Ghanaian qualitative study reported that both adult and young adult participants regarded vasectomy as an easy way for male partners to become promiscuous and cheat on women, because it rendered men incapable of having a child. ${ }^{(30)}$ The study also found that promiscuity could lead to women contracting sexually transmitted infections.

Our study was not without limitations. First, a majority of our participants were Malay and Muslim, with students of other ethnicities and religions constituting only a small percentage of the study population. Notwithstanding this, the makeup of our population closely reflected the overall demography of students at our college. Second, the proportion of Year 3 and 4 respondents was much higher than that of Year 5 respondents. Third, our participants were young, mostly unmarried, medically well-educated students who lacked real-life exposure. It is thus possible that our findings may not completely reflect their actual practice as doctors.

In conclusion, more than half of the medical students who participated in our study exhibited a positive attitude and displayed good acceptance of vasectomy as a method of contraception, even though it is not a popular choice among Malaysian couples. Although no demographic variable was associated with students' attitudes towards vasectomy and its acceptance, a significantly higher percentage of Year 5 students said that they would recommend vasectomy to relatives, friends and people close to them. As students' knowledge improved with their medical training, they developed attitudes that allowed them to accept the practice irrespective of their traditional, cultural and religious beliefs. Therefore, it is essential to educate medical students with evidence-based facts on male sterilisation, which is more cost-effective and less morbid than female sterilisation. This enables them to promote vasectomy to their patients and the public when they become doctors. A qualitative approach with focus group discussions involving students from different ethnicities and religions would help us to attain a better understanding of this subject. 
Table V. Relationship between demographic variables and the response to individual attitude questions among medical students $(n=330)$.

\begin{tabular}{|c|c|c|c|c|c|c|c|c|c|c|c|c|c|c|c|c|c|c|}
\hline \multirow{2}{*}{$\begin{array}{l}\text { Attitude } \\
\text { statement/ } \\
\text { response }\end{array}$} & \multicolumn{3}{|c|}{ Gender } & \multicolumn{4}{|c|}{ Academic yr } & \multicolumn{5}{|c|}{ Ethnicity } & \multicolumn{6}{|c|}{ Religion } \\
\hline & $\begin{array}{l}\text { Male } \\
(n=108)\end{array}$ & $\begin{array}{l}\text { Female } \\
(n=222)\end{array}$ & p-value & $\begin{array}{l}\text { Yr } 3 \\
(n=140)\end{array}$ & $\begin{array}{l}\operatorname{Yr} 4 \\
(n=114)\end{array}$ & $\begin{array}{l}\text { Yr } 5 \\
(n=76)\end{array}$ & p-value & $\begin{array}{l}\text { Malay } \\
(n=303)\end{array}$ & $\begin{array}{l}\text { Indian } \\
(n=10)\end{array}$ & $\begin{array}{l}\text { Chinese } \\
(n=9)\end{array}$ & $\begin{array}{l}\text { Other } \\
(n=8)\end{array}$ & p-value & $\begin{array}{l}\text { Islam } \\
(n=305)\end{array}$ & $\begin{array}{l}\text { Hinduism } \\
(\mathrm{n}=9)\end{array}$ & $\begin{array}{l}\text { Christianity } \\
(n=8)\end{array}$ & $\begin{array}{l}\text { Buddhism } \\
(n=6)\end{array}$ & $\begin{array}{l}\text { Other } \\
(n=2)\end{array}$ & p-value \\
\hline \multicolumn{19}{|c|}{ 1. Vasectomy is one of the best methods of contraception. } \\
\hline Agree & 85 (78.7) & $165(74.3)$ & 0.440 & 100 (71.4) & 93 (81.6) & $57(75.0)$ & 0.366 & $229(75.6)$ & $8(80.0)$ & $6(66.7)$ & 7 (87.5) & $0.951^{*}$ & $230(75.4)$ & $8(88.9)$ & 7 (87.5) & $3(50.0)$ & $2(100.0)$ & $0.553^{*}$ \\
\hline Disagree & $10(9.3)$ & $10(4.5)$ & & $10(7.1)$ & $4(3.5)$ & $6(7.9)$ & & $18(5.9)$ & $1(10.0)$ & $1(11.1)$ & $0(0.0)$ & & $18(5.9)$ & $1(11.1)$ & $0(0.0)$ & 1 (16.7) & $0(0.0)$ & \\
\hline Unsure & $13(12.0)$ & $47(21.2)$ & & $30(21.4)$ & $17(14.9)$ & $13(17.1)$ & & 56 (18.5) & $1(10.0)$ & $2(22.2)$ & $1(12.5)$ & & $57(18.7)$ & $0(0.0)$ & $1(12.5)$ & $2(33.3)$ & $0(0.0)$ & \\
\hline \multicolumn{19}{|c|}{ 2. Vasectomy is a good choice for couples who have completed their family. } \\
\hline Agree & $71(65.7)$ & 157 (70.7) & 0.431 & $84(60.0)$ & $87(76.3)$ & $57(75.0)$ & 0.051 & $207(68.3)$ & $7(70.0)$ & $6(66.7)$ & $8(100.0)$ & $0.731^{*}$ & $209(68.5)$ & $6(66.7)$ & $8(100.0)$ & $3(50.0)$ & $2(100.0)$ & $0.683^{*}$ \\
\hline Disagree & $14(13.0)$ & $19(8.6)$ & & $18(12.9)$ & $9(7.9)$ & $6(7.9)$ & & $31(10.2)$ & $1(10.0)$ & $1(11.1)$ & $0(0.0)$ & & $31(10.2)$ & $1(11.1)$ & $0(0.0)$ & $1(16.7)$ & $0(0.0)$ & \\
\hline Unsure & $23(21.3)$ & $46(20.7)$ & & $38(27.1)$ & $18(15.8)$ & $13(17.1)$ & & $65(21.5)$ & $2(20.0)$ & $2(22.2)$ & $0(0.0)$ & & $65(21.3)$ & $2(22.2)$ & $0(0.0)$ & $2(33.3)$ & $0(0.0)$ & \\
\hline \multicolumn{19}{|c|}{ 3. Vasectomy is forbidden according to your religion. } \\
\hline Agree & $30(27.8)$ & $26(11.7)$ & 0.001 & $35(25.0)$ & $13(11.4)$ & $8(10.5)$ & 0.010 & 55 (18.2) & $1(10.0)$ & $0(0.0)$ & $0(0.0)$ & $0.097^{*}$ & $55(18.0)$ & $1(11.1)$ & $0(0.0)$ & $0(0.0)$ & $0(0.0)$ & $0.029^{*}$ \\
\hline Disagree & 35 (32.4) & $93(41.9)$ & & $44(31.4)$ & $48(42.1)$ & $36(47.4)$ & & $116(38.3)$ & $7(70.0)$ & $3(33.3)$ & $2(25.0)$ & & $118(38.7)$ & $7(77.8)$ & $1(12.5)$ & $2(33.3)$ & $0(0.0)$ & \\
\hline Unsure & $43(39.8)$ & 103 (46.4) & & 61 (43.6) & $53(46.5)$ & $32(42.1)$ & & $132(43.6)$ & $2(20.0)$ & $6(66.7)$ & $6(75.0)$ & & $132(43.3)$ & $1(11.1)$ & $7(87.5)$ & $4(66.7)$ & $2(100.0)$ & \\
\hline \multicolumn{19}{|c|}{ 4. Vasectomy can be done under certain conditions even if it is forbidden according to your religion. } \\
\hline Agree & $64(59.3)$ & $99(44.6)$ & 0.037 & $84(60.0)$ & $49(43.0)$ & $30(39.5)$ & 0.011 & $156(51.5)$ & $3(30.0)$ & $2(22.2)$ & $2(25.0)$ & $0.003^{*}$ & $156(51.1)$ & $3(33.3)$ & $3(37.5)$ & 1 (16.7) & $0(0.0)$ & $0.002^{*}$ \\
\hline Disagree & $8(7.4)$ & $28(12.6)$ & & $10(7.1)$ & $13(11.4)$ & $13(17.1)$ & & $29(9.6)$ & $5(50.0)$ & $1(11.1)$ & $1(12.5)$ & & $30(9.8)$ & $5(55.6)$ & $0(0.0)$ & $1(16.7)$ & $0(0.0)$ & \\
\hline Unsure & 36 (33.3) & $95(42.8)$ & & $46(32.9)$ & $52(45.6)$ & $33(43.4)$ & & $118(38.9)$ & $2(20.0)$ & $6(66.7)$ & $5(62.5)$ & & $119(39.0)$ & $1(11.1)$ & $5(62.5)$ & $4(66.7)$ & $2(100.0)$ & \\
\hline \multicolumn{19}{|c|}{ 5. Vasectomy carries a bad impression for the person. } \\
\hline Agree & $27(25.0)$ & $22(9.9)$ & 0.001 & $19(13.6)$ & $17(14.9)$ & $13(17.1)$ & 0.149 & $46(15.2)$ & $0(0.0)$ & $3(33.3)$ & $0(0.0)$ & $0.072^{*}$ & $46(15.1)$ & $0(0.0)$ & $2(25.0)$ & $1(16.7)$ & $0(0.0)$ & $0.471^{*}$ \\
\hline Disagree & $53(49.1)$ & $134(60.4)$ & & $71(50.7)$ & $72(63.2)$ & $44(57.9)$ & & $166(54.8)$ & $9(90.0)$ & $5(55.6)$ & $7(87.5)$ & & $168(55.1)$ & $8(88.9)$ & $5(62.5)$ & $4(66.7)$ & $2(100.0)$ & \\
\hline Unsure & 28 (25.9) & $66(29.7)$ & & $50(35.7)$ & $25(21.9)$ & $19(25.0)$ & & $91(30.0)$ & $1(10.0)$ & $1(11.1)$ & $1(12.5)$ & & $91(29.8)$ & $1(11.1)$ & $1(12.5)$ & 1 (16.7) & $0(0.0)$ & \\
\hline \multicolumn{19}{|c|}{ 6. Vasectomy is an unusual contraceptive practice in Malaysia. } \\
\hline Agree & $51(47.2)$ & $90(40.5)$ & 0.515 & $54(38.6)$ & $47(41.2)$ & $40(52.6)$ & 0.327 & $126(41.6)$ & $4(40.0)$ & $8(88.9)$ & $3(37.5)$ & $0.087^{*}$ & $126(41.3)$ & $3(33.3)$ & $6(75.0)$ & $5(83.3)$ & $1(50.0)$ & $0.144^{*}$ \\
\hline Disagree & $21(19.4)$ & $49(22.1)$ & & $32(22.9)$ & $23(20.2)$ & $15(19.7)$ & & $65(21.5)$ & $1(10.0)$ & $1(11.1)$ & $3(37.5)$ & & $66(21.6)$ & $1(11.1)$ & $2(25.0)$ & $1(16.7)$ & $0(0.0)$ & \\
\hline Unsure & $36(33.3)$ & $83(37.4)$ & & $54(38.6)$ & $44(38.6)$ & $21(27.6)$ & & $112(37.0)$ & $5(50.0)$ & $0(0.0)$ & $2(25.0)$ & & $113(37.0)$ & $5(55.6)$ & $0(0.0)$ & $0(0.0)$ & $1(50.0)$ & \\
\hline \multicolumn{19}{|c|}{ 7. A man who has vasectomy would be prone to be promiscuous. } \\
\hline Agree & $27(25.0)$ & $43(19.4)$ & 0.492 & $30(21.4)$ & $22(19.3)$ & $18(23.7)$ & 0.000 & $60(19.8)$ & $5(50.0)$ & $2(22.2)$ & $3(37.5)$ & $0.022^{*}$ & $61(20.0)$ & $5(55.6)$ & $1(12.5)$ & $2(33.3)$ & $1(50.0)$ & $0.030^{*}$ \\
\hline Disagree & $25(23.1)$ & $53(23.9)$ & & $18(12.9)$ & $32(28.1)$ & $28(36.8)$ & & $68(22.4)$ & $2(20.0)$ & $5(55.6)$ & $3(37.5)$ & & 69 (22.6) & $2(22.2)$ & $5(62.5)$ & $2(33.3)$ & $0(0.0)$ & \\
\hline Unsure & $56(51.9)$ & $126(56.8)$ & & $92(65.7)$ & $60(52.6)$ & $30(39.5)$ & & $175(57.8)$ & $3(30.0)$ & $2(22.2)$ & $2(25.0)$ & & $175(57.4)$ & $2(22.2)$ & $2(25.0)$ & $2(33.3)$ & $1(50.0)$ & \\
\hline
\end{tabular}

All values, except p-values, are presented as no. (\%). *Fisher's exact test 


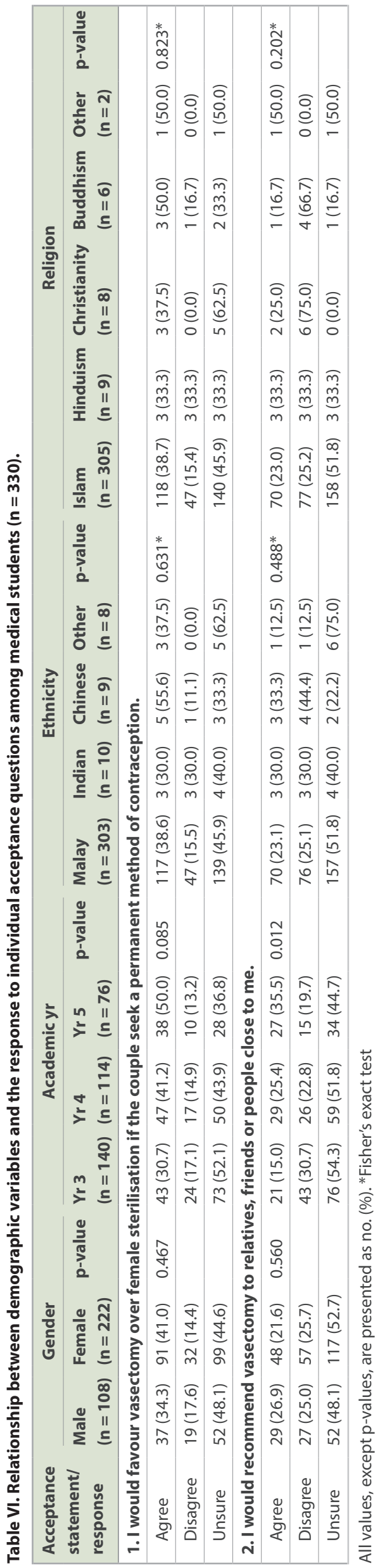

\section{REFERENCES}

1. Malaysia Population [online]. Available at: https://countrymeters.info/en/Malaysia. Accessed March 28, 2016.

2. Department of Statistics, Malaysia. Press Release: Vital Statistics, Malaysia, 2014. Available at: https://www.dosm.gov.my/v1/index.php? r=column/ pdfPrev\&id=akZOby9EYThSQ3V3WHpZSEdjeU50dz09. Accessed March 28, 2016.

3. Najimudeen M, Sachchithanantham K. An insight into low contraceptive prevalence in Malaysia and its probable consequences. Int J Reprod Contracept Obstet Gynecol 2014; 3:493-6.

4. Department of Statistics, Malaysia. Population Distribution and Basic Demographic Characteristic Report 2010. Available at: https:// www.dosm.gov.my/v1/index.php?r=column/ctheme \&menu_ $\mathrm{i} d=\mathrm{L} 0 \mathrm{ph}$ e U $43 \mathrm{NWJ}$ J R W V S Z k IW d z Q 4 TIh U U T 09 \& bu I _ id=MDMxdHZjWTk1SjFzTzNkRXYzcVZjdz09. Accessed March 28, 2016.

5. Department of Statistics, Malaysia. Population distribution by religion, Malaysia, 2010. Available at: http://www.statistics.gov.my/censusatlas/religion.php. Accessed March 28, 2016.

6. Srikanthan A, Reid RL. Religious and cultural influences on contraception. J Obstet Gynaecol Can 2008; 30:129-37.

7. Hogmark S, Klingberg-Allvin M, Gemzell-Danielsson K, Ohlsson H, Essén B. Medical students' knowledge, attitudes and perceptions towards contraceptive use and counselling: a cross-sectional survey in Maharashtra, India. BMJ Open 2013; 3:e003739.

8. Ebeigbe PN, Igberase GO, Eigbefoh J. Vasectomy: a survey of attitudes, counseling patterns and acceptance among Nigerian resident gynaecologists. Ghana Med J 2011; 45:101-4.

9. Keramat A, Zarei A, Arabi M. Barriers and facilitators affecting vasectomy acceptability (a multi stages study in a sample from north eastern of Iran), 2005-2007. Asia Pac Fam Med 2011; 10:5

10. Murthy SR, Rao MD. An analysis of factors influencing the acceptability of vasectomy in Andhra Pradesh. Health Population 2003; 26:162-82.

11. Smith GL, Taylor GP, Smith KF. Comparative risks and costs of male and female sterilization. Am J Public Health 1985; 75:370-4

12. World Health Organization. Family planning/Contraception. Available at: https:// www.who.int/mediacentre/factsheets/fs351/en/. Accessed January 25, 2016.

13. Sneyd MJ, Cox B, Paul C, Skegg DC. High prevalence of vasectomy in New Zealand. Contraception 2001; 64:155-9.

14. Eisenberg ML, Lipshultz LI. Estimating the number of vasectomies performed annually in the United States: data from the National Survey of Family Growth. J Urol 2010; 184:2068-72.

15. Malhotra A. The sterilization gap infogram. Delhi's 'mega' vasectomy camp and why Indian men don't get sterilized. In: The Wall Street Journal [online]. Available at: https://blogs.wsj.com/indiarealtime/2014/11/13/delhis-mega-vasectomy-camp-andwhy-indian-men-dont-get-sterilized/. Accessed March 21, 2016.

16. Anderson JE, Jamieson DJ, Warner L, et al. Contraceptive sterilization among married adults: national data on who chooses vasectomy and tubal sterilization. Contraception 2012; 85:552-7

17. Valsangkar S, Sai SK, Bele SD, Bodhare TN. Predictors of no-scalpel vasectomy acceptance in Karimnagar district, Andhra Pradesh. Indian J Urol 2012; 28:292-6.

18. Tijani KH, Ojewola RW, Yahya GL, Oluwole AA, Odusanya B. Attitudes and acceptance of Nigerians towards vasectomy--a comparison of married men and women in Lagos. East Afr Med J 2013; 90:89-94.

19. Okunlola MA, Awoyinka SB, Owonikoko KM. Awareness and practice of vasectomy among married male health workers at the University College Hospital, Ibadan, Nigeria. Niger Postgrad Med J 2009; 16:203-6.

20. Anderson JE, Warner L, Jamieson DJ, et al. Contraceptive sterilization use among married men in the United States: results from the male sample of the National Survey of Family Growth. Contraception 2010; 82:230-5.

21. Santomauro M, Masterson J, Marguet C, Crain D. Demographics of men receiving vasectomies in the US military 2000-2009. Curr Urol 2012; 6:15-20.

22. Khalifa MA. Attitudes of urban Sudanese men toward family planning. Stud Fam Plann 1988; 19:236-43.

23. Odu OO, ljadunola KT, Komolafe JO, Adebimpe WT. Men's knowledge of and attitude with respect to family planning in a suburban Nigerian community. Niger J Med 2006; 15:260-5.

24. Christiana O, Sonachi C, Chinomso N. Knowledge and attitude of men about vasectomy as a method of family planning among married men working in Babcock University, Ogun state, Nigeria. Int J Nurs Midwifery 2014; 7:30-5.

25. Birth Control. Available at: https://www.al-islam.org/islamic-edicts-on-familyplanning/birth-control. Accessed January 5, 2016.

26. BBC. Religions: contraception. Buddhism and contraception. Available at: http://www. bbc.co.uk/religion/religions/buddhism/buddhistethics/contraception.shtml. Accessed January 5, 2016

27. Focus on the Family. Practical, Moral, and Spiritual Implications of Sterilization. Available at: https://www.focusonthefamily.com/family-q-and-a/relationships-andmarriage/practical-moral-and-spiritual-implications-of-sterilization. Accessed January $11,2019$.

28. Scott B Alam D, Raman S. Factors affecting acceptance of vasectomy in Uttar Pradesh: insights from community-based, participatory qualitative research. The RESPOND Project Study Series: Contributions to Global Knowledge-Report No. 3. Available at: http://www.respond-project.org/pages/files/6_pubs/research-reports/Study3-PEERNSV-Report-May2011-FINAL.pdf. Accessed January 5, 2016.

29. Perry B, Packer C, Chin Quee D, et al. Recent experience and lessons learned in vasectomy programming in low-resource setting: a document review. Available at: https://www.fhi360.org/sites/default/files/media/documents/resource-vasectomy-litreview-final.pdf. Accessed January 16, 2016.

30. Asare O, Otupiri E, Apenkwa J, Odotei-Adjei R. Perspectives of urban Ghanaian women on vasectomy. Reprod Health 2017; 14:21. 